\title{
AUS DEN STUDIEN ZUR ERFORSCHUNG DER ENKLAVE DER LAUSITZER KULTUR IN DER UMGEBUNG VON KRAKAU TRANSKARPATISCHE EINFLÜSSE
}

\begin{abstract}
Jacek Górski
DOI: https://doi.org/10.31577/szausav.2019.suppl.1.9

Keywords: Lusatian culture, Bronze Age, cemetery

From studies on the enclave of the Lusatian culture in Kraków area : Transcarpathian influences

The origins of the Lusatian culture in Kraków area are related to the migration of population groups from Silesia or Moravia in the phase D of the Bronze Age (Br D). Set of basic vessels and the majority of bronze artefacts have its equivalents in the western zone of the Lusatian culture. Parallels in Slovakia, in upper Váh and Poprad area have only beaked axes with symmetrical socket inlet and several vessels similar to those of the Piliny Culture. Numerous vessels with parallels in the Transcarpathian region were discovered in recently investigated big cemetery of the Lusatian culture in Targowisko, distr. Wieliczka. The vessels are dated to phase A2 of the Hallstatt period (Ha A2).
\end{abstract}

I

In der frühen Phase der Lausitzer Kultur wird auf dem Gebiet westlichen Kleinpolens die Krakauer (Kraków) Subgruppe unterschieden, die in der taxonomischen Gliederung zur schlesischen Gruppe gerechnet wird (Gedl 1975, 110). Im archäologischen Fundmaterial sind diese schlesischen Anknüpfungen deutlich nachweisbar, vor allem für die zwei ersten Phasen, nämlich Iwanowice- und ZofipoleRaciborsko-Phase (Gedl 1982, 21-24, Abb. 13). Ihre Datierung wird in die Phase D der Bronzezeit und Phasen A1 und A2 der Hallstattzeit festgelegt. Damals entstanden im westlichen Kleinpolen in den Grenzgebieten der Trzciniec-Ökumene bzw. auf den nicht besiedelten Terrains neue Siedlungsstrukturen (Abb. 1). Die Siedlungen und Brandgräberfelder wurden dort in einem vorher völlig unbesiedelten Gelände (,,aus wilder Wurzel“) angelegt. Deshalb nimmt man an, dass ihr Ursprung mit der Migration der Träger der Lausitzer Kultur aus Schlesien oder Mähren und der Kolonisation der Umgebung von Krakau zusammenhängt (Gedl 1967, 289-293; 1975, 110; 1982, 21, 22; Górski 2002; Kozłowski 1928, 80; Mrówka 2013; Rydzewski 1983, 216, 217). Dazu sollte es in der Phase D der Bronzezeit kommen (Górski 2002, 23; 2007, 38-45; 2010, 111).

Für starke Verbindungen mit Schlesien spricht die Eigenart der materiellen Kultur. Die in den Siedlungen und auf den Gräberfeldern vorkommenden Gefäße besitzen genaue Analogien in der westlichen Verbreitungszone der Lausitzer Kultur (Abb. 2). Auch die Mehrheit der Bronzegegenstände weist die westliche Provenienz auf (Abb. 3).

II

Die Terrains im Einzugsgebiet des Weichsel-Oberlaufs waren seit dem Beginn des Neolithikums mit den südlich der Karpaten gelegenen Zonen kulturell sehr stark verbunden. Eine andere Situation zeigt sich im Endneolithikum. Trotzt der Migration der Bevölkerungsgruppen der schnurkeramischen Kultur zu den Südhängen der Karpaten und ins Theiß-Tal (Machnik 1993, 243) wurden in dieser Zeit in Kleinpolen keine kulturellen Beziehungen zu den transkarpatischen Gebieten beobachtet. Die Achsen der weiträumigen Kontakte verliefen damals entlang der Breitenkreise. Die Entwicklung, zu Beginn der Bronzezeit in Südostpolen und in der Slowakei, einer Kultureinheit in Form des epischnurkeramischen 
karpatenländischen Kulturkreises stellte das Netz interregionaler transkarpatischer Kontakte wieder her. Das führte, nach der Etablierung der Otomani-Füzesabony-Kultur, bestimmt zur erneuten Vermittlung der transkarpatischen Einflüsse nach Norden (Górski 2003; 2012; Górski/Makarowicz 2007; Makarowicz 1999).

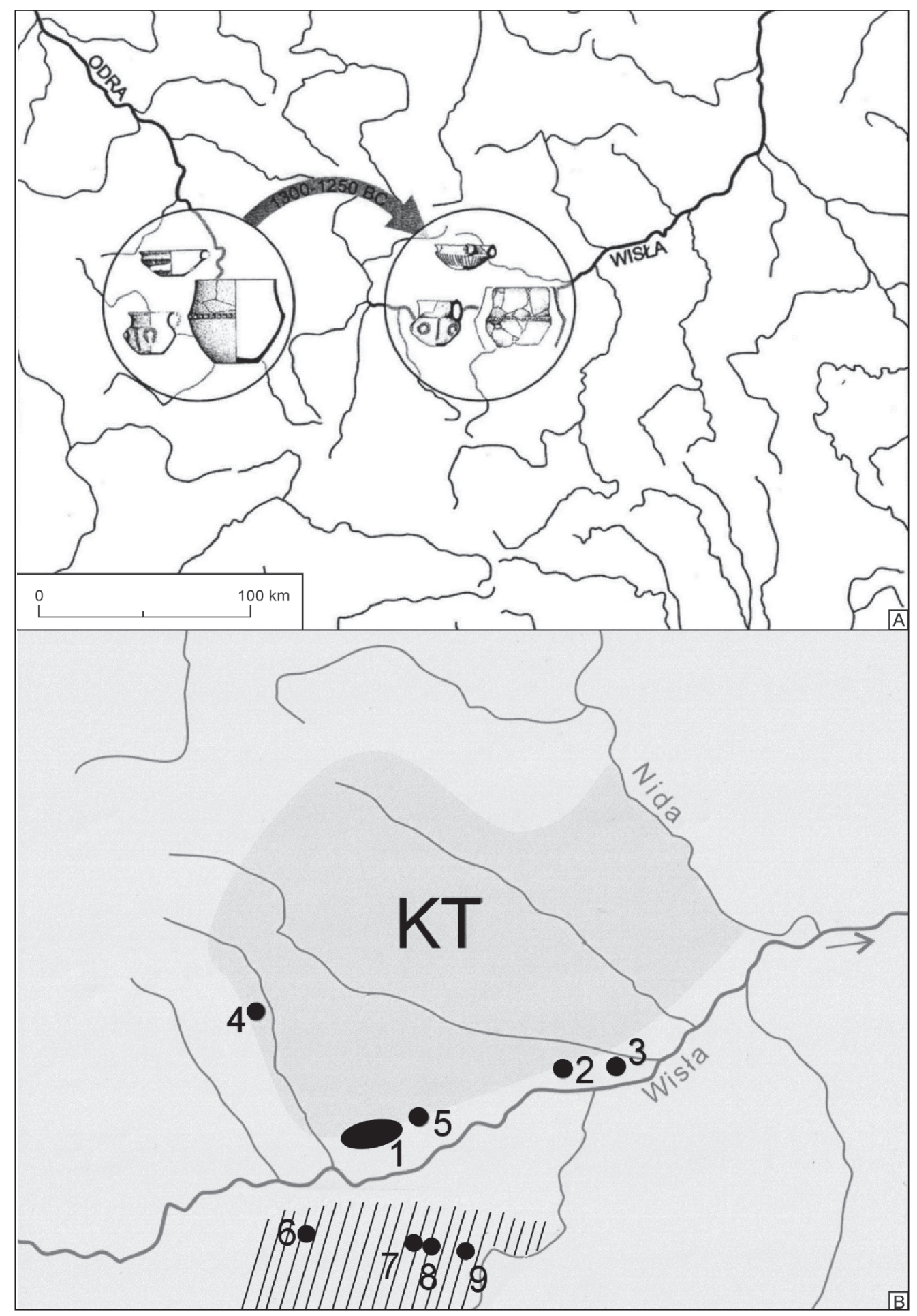

Abb. 1. A - Expansion der Lausitzer Kultur in westliches Kleinpolen. B - Siedlungsbereich der frühen Phase der Lausitzer Kultur (Schraffur) vor dem Hintergrund des geschlossenen Siedlungsraumes der Trzciniec Kultur (KT) in der Umgebung von Krakau. Die ältesten Fundstellen der Lausitzer Kultur: 1 - Kraków-Nowa Huta; 2 - Książnice Wielkie; 3 - Witów; 4 - Iwanowice-Wysyłek; 5 - Zofipole und Igołomia; 6 - Kraków-Bieżanów; 7 - Zagórze; 8 - Brzezie; 9 - Targowisko. 
Die Herausbildung des Urnenfelderkulturkreises wurde auf polnischen Gebieten durch die Einflussnahmen aus dem Westen angeregt. Die ältesten Fundmaterialien der Lausitzer Kultur werden in Schlesien freigelegt. Von da aus verbreitete sich die neue Kulturströmung infolge unterschiedlicher Vorgänge (Akkulturation, Migration) nach Westen und Norden. In den Phasen Bz D und Ha A1 entwickelte sich ein Mosaik von verschiedenen Kulturgruppierungen, deren gemeinsames Merkmal die Brandbestattung war. Manchmal, und das gilt auch für die Gebiete bei Krakau, hat man mit der Übernahme des Kulturmodels infolge der Migration zu tun. Stärkere transkarpatische Einflüsse sind in dieser Zeitspanne nur im Bereich der Tarnobrzeg Lausitzer Kultur erkennbar (Przybyła 2009b, 283-297).

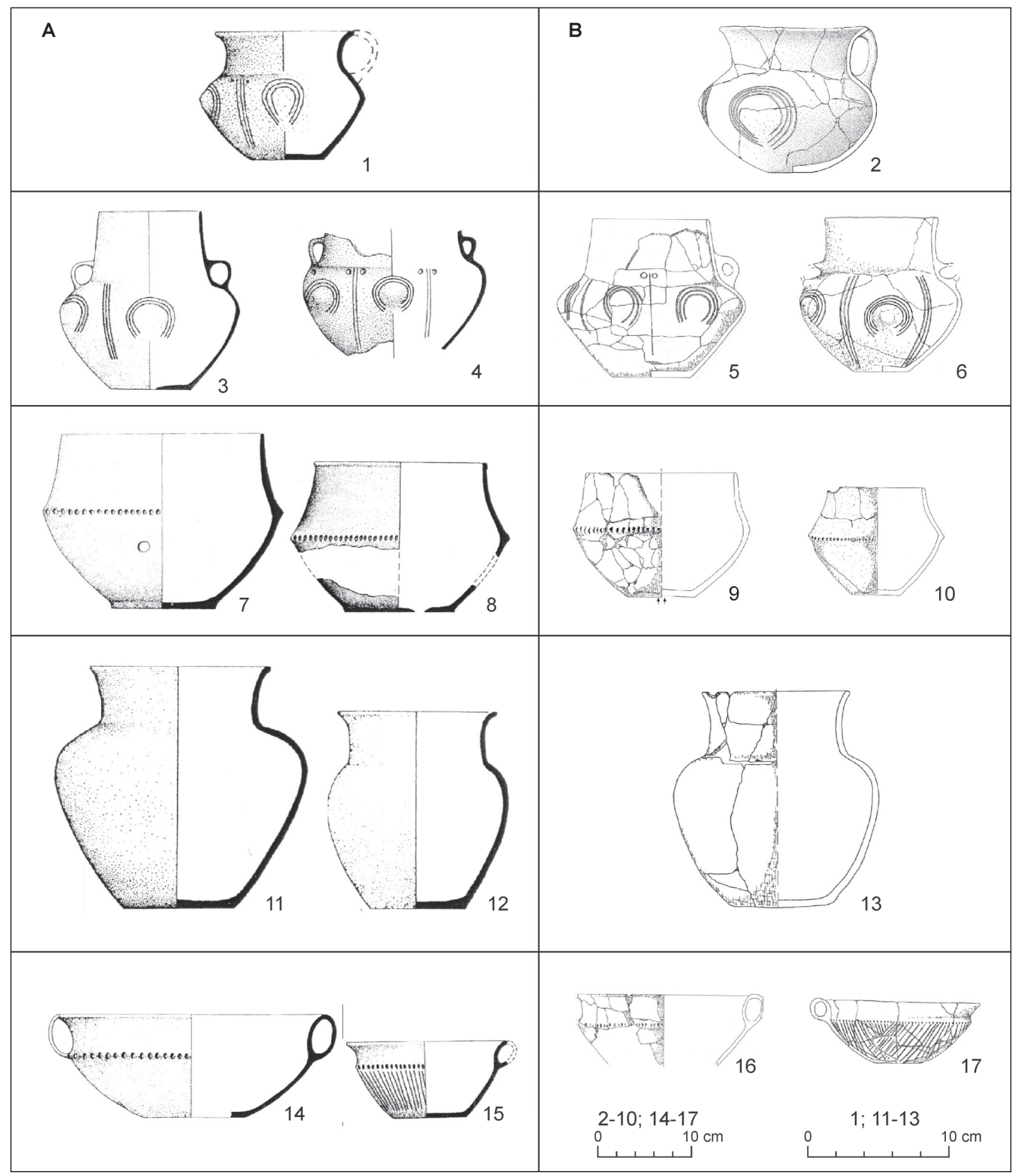

Abb. 2. Vergleich der Keramik aus der frühen Phase der Lausitzer Kultur aus der Umgebung von Krakau (B) und aus Kietrz, Kr. Głubczyce (A; nach Gedl 1992; Górski 1994; 2014). 
Infolge neuer Freilegungen, insbesondere dank der Ausgrabungsarbeiten im Vorfeld des Baus der Autobahn A4 in der Nähe von Krakau, beobachtet man einen Zuwachs an Fundmaterialien, was die Beziehungen zwischen den slowakischen Gebieten und der bei Krakau exsistierenden Enklave der Lausitzer Kultur in einem neuen Licht erscheinen lässt.

III

Die Verbreitung der Bronzegegenstände deckt sich zeitlich mit dem Auftauchen der Funde der frühen Lausitzer Kultur vom „schlesischen“ Typ. Die Mehrheit der Bronzenadeln besitzt Analogien in der westlichen Verbreitungszone der Lausitzer Kultur (vgl. Essen 1985). Die detaillierte Analyse beider Hortfunde aus Witów belegt die Ähnlichkeit der schlesischen und kleinpolnischen Hortfunde aus dieser Zeit (Blajer 1999, 125, 126). Der aus diesen Komplexen bekannte Ringschmuck zeigt Ähnlichkeit mit den Exemplaren aus Oberschlesien und aus benachbarten mährischen Gebieten (sog. Ringgarnituren vom Typ Kosmonosy - Blajer 1994, 125, 126).

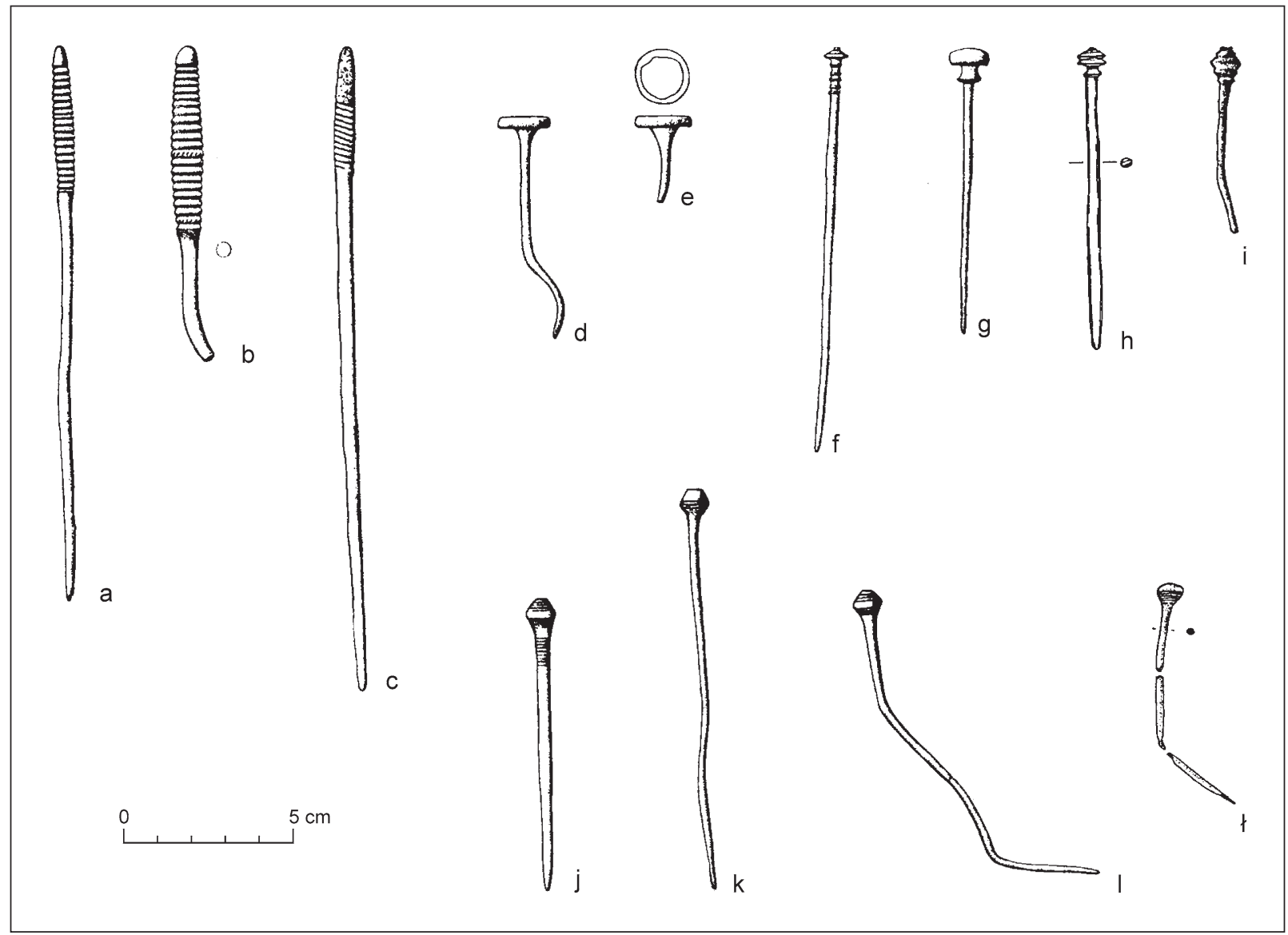

Abb. 3. Bronzeerzeugnisse der frühen Phase der Lausitzer Kultur aus der Umgebung von Krakau (nach Górski 2007; Konieczny 2014).

Eine andere Provenienz weisen nur die Schnabelbeile mit symmetrischem Tüllenmund auf (Abb. 4). Sie werden in der Regel in die Phasen Ha A1-Ha A2 der Hallstattzeit datiert (Kuśnierz 1989, 149), sie kommen jedoch auch in etwas jüngeren Hortfunden sporadisch zum Vorschein (Blajer 1999, 24-28). Derartige Beile sind aus einigen in der Umgebung von Krakau freigelegten Hortfunden (Biskupice, Chruszczyna Mała, Witów; Blajer 1999, 28), wie auch als Streufunde bekannt. Eins von ihnen wurde neulich in der Grubenverfüllung des Grabs Nr. 17 in Targowisko entdeckt (Konieczny 2014, Taf. 8: b). 
Dieses Exemplar besaß deutliche Gussnähte auf der Seite. Für diese Beile gibt es zahlreiche Analogien vor allem auf den slowakischen Gebieten, am oberen Waag und Poprad. Ihre Anhäufung in dieser Zone ist auf die lokale Herstellung dieser Gegenstände zurückzuführen (Kuśnierz 1989, 144, 149, Abb. 1).
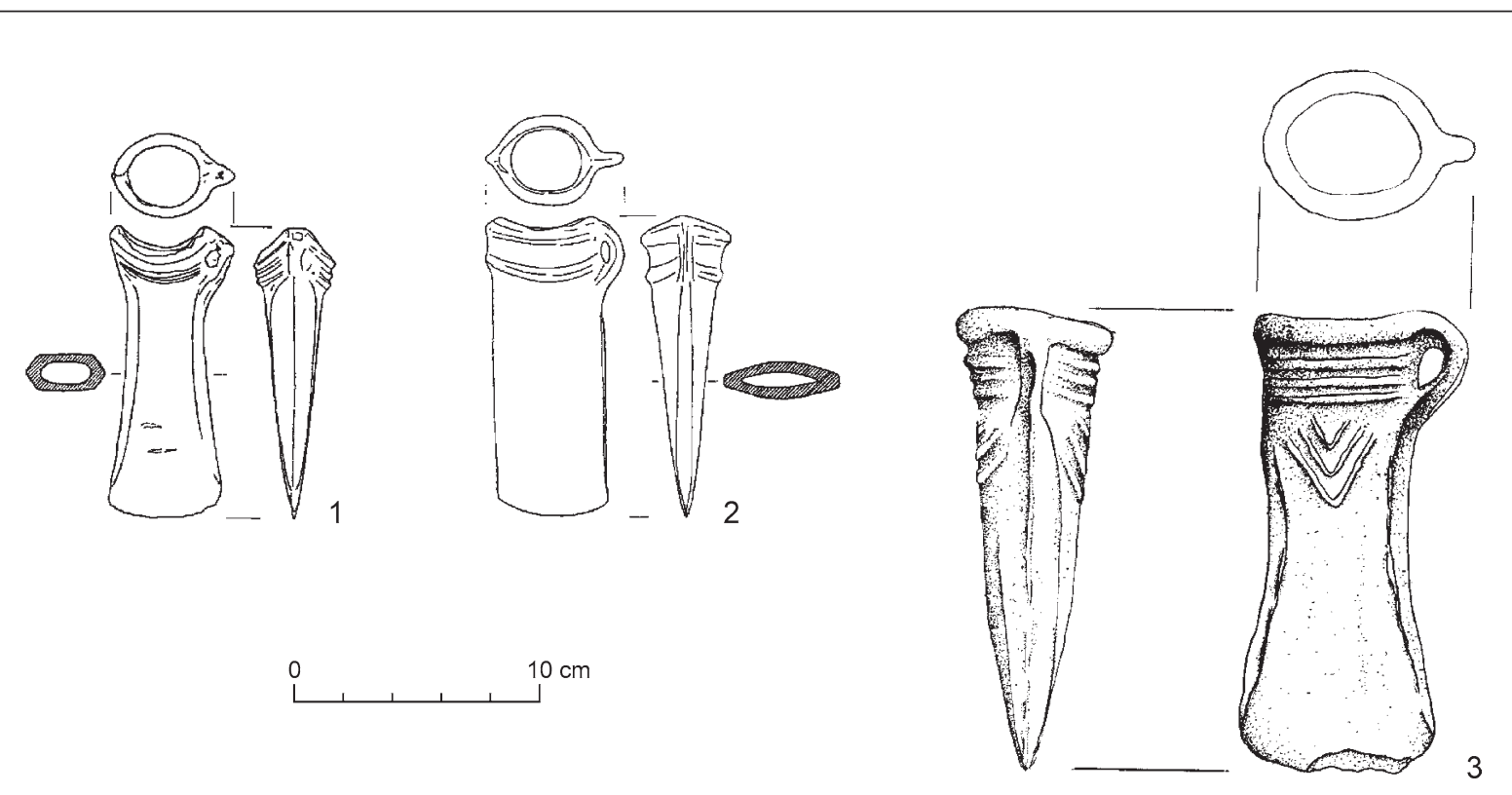

Abb. 4. Schnabelbeile aus der Umgebung von Krakau, Auswahl. 1 - Chruszczyna Mała; 2 - Biskupice; 3 - Targowisko (nach Blajer 1999; Kuśnierz 1989).

In der Karpatenzone hat man auf die Anwesenheit der bronzenen Hort- und Streufunde der PilinyKultur bei gleichzeitiger spärlicher Zahl charakteristischer Keramik hingewiesen (Gedl 1998, 139). Die Keramik ist hauptsächlich aus einigen Grabkomplexen des Brandgräberfeldes in Chełm, Kr. Nowy Sącz, bekannt (Szymaszkiewicz 1985). In der Piliny-Kultur findet man auch die Parallelen für die Keramik aus manchen Siedlungsfundstellen (Zawada Lanckorońska; Bak 1992). In der Siedlungszone der Krakauer Subgruppe der Lausitzer Kultur legte man auf der Anhöhe Góra Chełm (Kr. Bochnia) ein Gefäß mit Brandbestattung frei, das ebenfalls Analogien in der Piliny-Kultur besitzt (Rodak 2003).

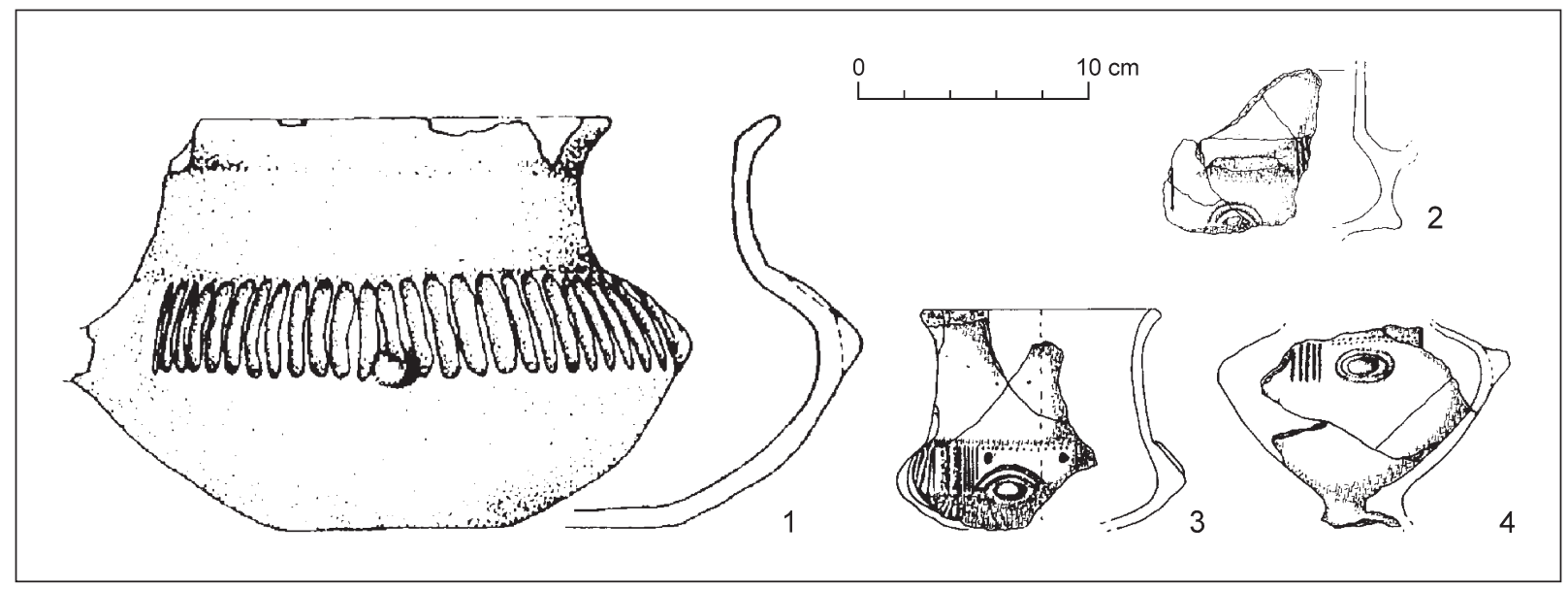

Abb. 5. Krüge der Piliny-Kultur von der Fundstelle in Targowisko (2-4) und Góra Chełm (1; nach Górski 2014; Rodak 2003). 
Die Anhöhe Góra Chełm ist ein charakteristischer Landschaftspunkt, der sich deutlich über das umliegende Gelände erhebt. Auf der anderen Flussseite befindet sich in Targowisko, Fst. 10-12, Kr. Wieliczka (Górski 2014), ein Siedlungskomplex. Er besteht aus zwei gleichzeitig genutzten Siedlungen, die in der Phase D der Bronzezeit angelegt wurden, wie auch aus einem in die Phasen Bz D-Ha A2 datierten Brandgräberfeld, auf dem über 650 Gräber freigelegt wurden. Im Kontext des behandelten Themas soll man auf einige Krüge mit Knubbenverzierung aufmerksam machen, die in der Siedlungszone der Fundstelle entdeckt wurden (Abb. 5; Fst. 10; Górski 2014, Taf. 43: 10; 61: 4; 62: 4). Bezüglich der Morphologie und Stilrichtung weichen sie von den Gefäßen der Lausitzer Kultur ab. Mindestens zwei von ihnen besitzen Hohlfüße. Sie ähneln den aus Piliny-Kultur bekannten Gefäßen. Dort sind Hohlfußgefäße ebenfalls vertreten (Furmánek 1977, Taf. XIV: 1; Gašaj 1985, Abb. 3: 2; Szymaszkiewicz 1985, Taf. 3: 1).

Auf die transkarpatische Herkunft weist man auch in Bezug auf wenige wannenförmige Gefäße hin (Gawlik/Gryglewski 2010, 342-346). Im frühlausitzischen Kontext wurden sie an einigen Fundstellen in Kraków-Nowa Huta (Bazielich 1992, Taf. XV: 12; Rachwaniec 1985, Taf. XVI: 5; XXVI: 1; XXXIII: 14), in Witów, Kr. Proszowice (Gawlik/Godlewski 2010, Abb. 4: 4; 6: 4), Targowisko, Fst. 10 und 11 (Górski 2014, Abb. 29; Taf. 45: 11; 55: 8; 57: 2; Górski/Schellner 2014, Taf. 22: 1; 27: 2), in Zagórz, Fst. 2, Kr. Wieliczka (Górski 2018, Taf. 25: 10; 18: 1), geborgen.

Die oben angeführten Artefakte sind im Bereich der ältesten Phase der Lausitzer Kultur in der Umgebung von Krakau bisher die einzigen Beispiele für die Keramik mit transkarpatischen Merkmalen. Ihre Zahl ist spärlich und sie bestätigen die Dominanz der westlichen Richtung der Einflüsse in der Anfangsphase dieser Kultur. Nichtsdestotrotz soll, im Kontext der frühlausitzschen Materialien, die Anwesenheit der bisher nicht registrierten Merkmale der Piliny- Kultur in Targowisko betonnt werden. Nicht unbedeutend war hier wahrscheinlich eine besondere Lage der Fundstelle am großen Fluss (Raba), der einen natürlichen Verkehrsweg die Nord-Süden-Achse entlang bildete.

Seit vielen Jahren richtet man die Aufmerksamkeit auf die in der Umgebung von Krakau freigelegte Keramik mit transkarpatischen Zügen, die in der älteren Fachliteratur der Gáva-Kultur zugeschrieben wurde (Bazielich 1982a; 1982b; 1984, dort ältere Fachliteratur). Heute wird sie dagegen auf den Belegiš-Stil bezogen (Przybyła 2009a). Unterschiedliche Aspekte dieses Problems wurden neulich ausführlich erörtert (Przybyła 2007; 2009a; 2009b).

\begin{tabular}{|l|l|l|l|l|l|l|l|l|l|l|l|l|l|l|}
\hline & $\mathrm{A} 1$ & $\mathrm{~A} 2$ & $\mathrm{~A} 5$ & $\mathrm{~A} 6$ & $\mathrm{~A} 3$ & $\mathrm{~A} 4$ & $\mathrm{~A} 8$ & $\mathrm{~B} 7$ & $\mathrm{~B} 10$ & $\mathrm{~B} 11$ & $\mathrm{~B} 13$ & $\mathrm{~B} 12$ & $\mathrm{~B} 9$ & $\mathrm{~B} 14$ \\
\hline $\mathrm{A} 1$ & & & & & & & & & & & & & & \\
\hline A2 & & & & & & & & & & & & & & \\
\hline A5 & & & & & & & & & & & & & & \\
\hline A6 & & & & & & & & & & & & & & \\
\hline A3 & & & & & & & & & & & & & & \\
\hline A4 & & & & & & & & & & & & & & \\
\hline B8 & & & & & & & & & & & & & & \\
\hline B7 & & & & & & & & & & & & & & \\
\hline B10 & & & & & & & & & & & & & & \\
\hline B11 & & & & & & & & & & & & & & \\
\hline B13 & & & & & & & & & & & & & & \\
\hline B12 & & & & & & & & & & & & & & \\
\hline B9 & & & & & & & & & & & & & & \\
\hline B14 & & & & & & & & & & & & & & \\
\hline
\end{tabular}

Abb. 6. Tabelle mit der Darstellung der Korrelation mancher Keramikmerkmale in den Grabkomplexen auf dem Gräberfeld in Targowisko (schwarze Rechtecke - Ergebnisse der positiven Zusammenhänge), Erläuterungen auf Abb. 7 (nach Górski 2014, Taf. 1).

Aufgrund der Analyse der Grabkomplexe in Targowisko kann die Chronologie des Zuflusses an Materialien mit transkarpatischen Merkmalen, wie auch der sie begleitende Fundkontext bestimmt werden (Abb. 6; 7). Auf dem Schaubild zeichnen sich zwei Gruppen deutlich korrelierter Merkmale ab. Die erste Merkmalgruppe entspricht der Phase Iwanowice-Wysyłek (Bz D-Ha A1) und die zweite der 
Phase Zofipole-Raciborsko (Ha A2). Die beiden mit den Materialien aus der älteren und jüngeren Phase übereinstimmenden Gruppen sind miteinander schwach korrelierbar. Beide Stilrichtungen bildeten auf dem Gräberfeld keine getrennten Zonen und die Gräber, in denen sie in Erscheinung traten, waren oft benachbart. Das zeugt davon, dass diese Wandlungen im Bereich derselben Gemeinschaft, die ihre Bestattungsrituale, darunter auch räumliche, bewahrt hat, zustande kamen.

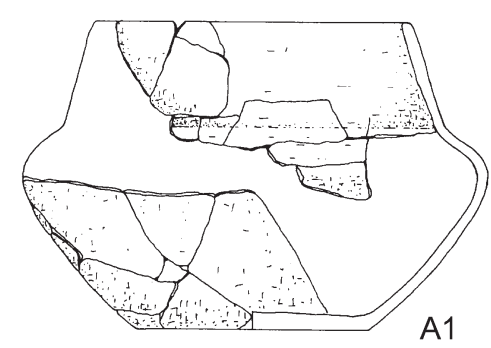

A1
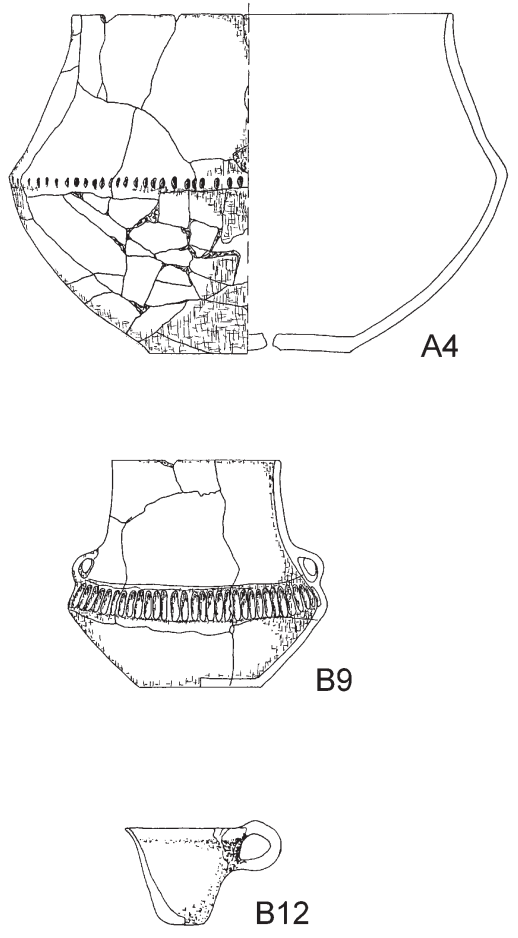
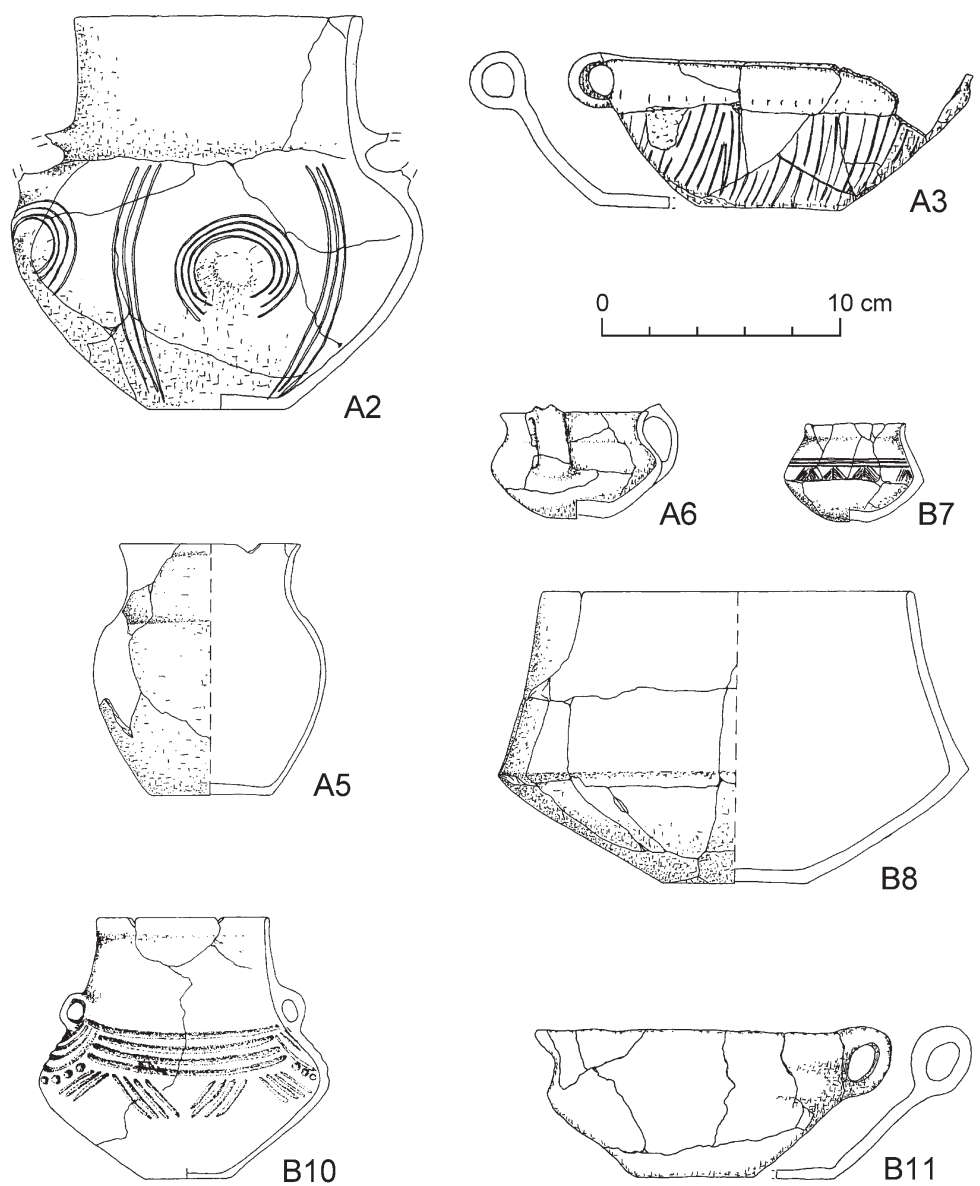

B10

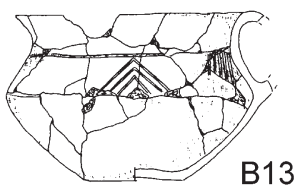

Abb. 7. Targowisko, Fst. 10-12, Kr. Wieliczka. Keramikmerkmale für die Abb. 6. A1 - henkellose Amphore, konischer Hals, sanft geknickter Bauch; A2 - für den "schlesischen Stil” charakteristische; Buckelverzierung A3 - profilierte Schüssel mit Rillen am Knick und/oder mit Ritzlinien; A4 - Vase mit Rillen am Knick; A5 - Topf mit sanfter Profilierung oder mit dem akzentuierten Übergang zwischen dem Bauch und dem Hals; A6 - unverzierter Becher/Krug mit scharfem Bauchknick; B7 - Zofipole-Vase oder ihre Fragmente; B8 - doppelkonische Vase mit geradem Hals; B9 - Gefäß mit senkrechter Rillenverzierung B10 - andere „südliche” Verzierungsmerkmale; B11 - unverzierte profilierte Schüssel mit, bzw. ohne Henkel; B12 - einteiliger Becher; B13 - Sparrenverzierung; B14 - konische Henkelschüssel mit zylindrisch geformter Randpartie (nach Górski 2014, Abb. 1).

Das Keramikgut der Zofipole-Raciborsko-Phase ist sehr charakteristisch und weist zwei unterschiedliche Stilrichtungen auf (Abb. 8; 9). Die erste bildet die Keramik mit lokalen Merkmalen. Das sind vor allem kleine dünnwandige sog. Zofipole-Vasen mit Verzierung in Gestalt von Ritzlinien und verschieden arrangierten Strichgruppen, aber auch große doppelkonische unverzierte Vasen mit bzw. ohne Henkeln, 
unverzierte profilierte Schüsseln, wie auch einteilige, meistens konische Becher mit dem Schlaufenhenkel. Selten zu treffen sind sanft profilierte Töpfe. Die zweite Stilrichtung ist stark ausgeprägt. Zu dieser Gruppe gehören Gefäße mit breiten senkrechten Rillen. Die oft senkrecht gezogenen Rillen werden durch andere Motive begleitet: Buckel mit Bogenreifen, waagerechte Rillen am Hals, manchmal auch Grübchen. Reich verziert sind in der Regel nur Amphoren oder parallele henkellose Formen. In Bezug auf Mikromorphologie dieser Gefäße ist der manchmal vorkommende kragenartig geformte Rand charakteristisch. Verziert sind auch große Schüsseln, die auf dem Innenboden konzentrische Rillen und breite „verschlungene“ Rillen aufweisen. Die in beiden Stilrichtungen hergestellten Gefäße kamen sehr oft zusammen zum Vorschein. Deshalb soll man feststellen, dass die Exemplare mit südlichen Merkmalen keinen separaten chronologischen Horizont vertreten. Besonders beachtenswert sind die Gefäße mit hornartigen Knubben (Konieczny 2014, Taf. 38: a; 260: b; 262: a).

\section{Grób 273}

Poziom C

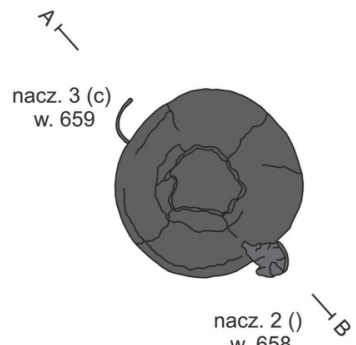

Profil A-B
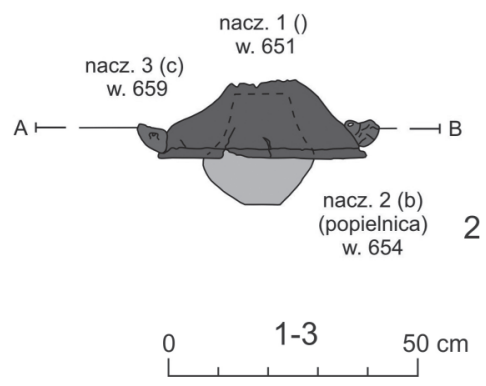

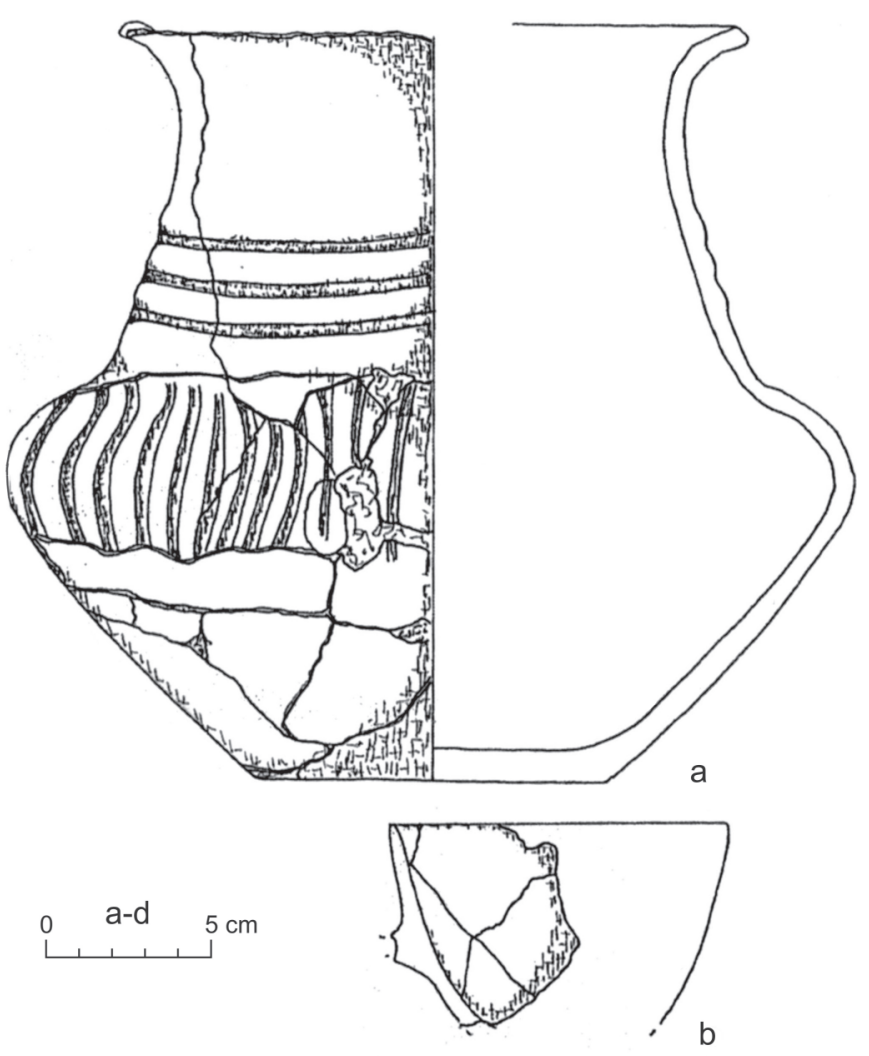

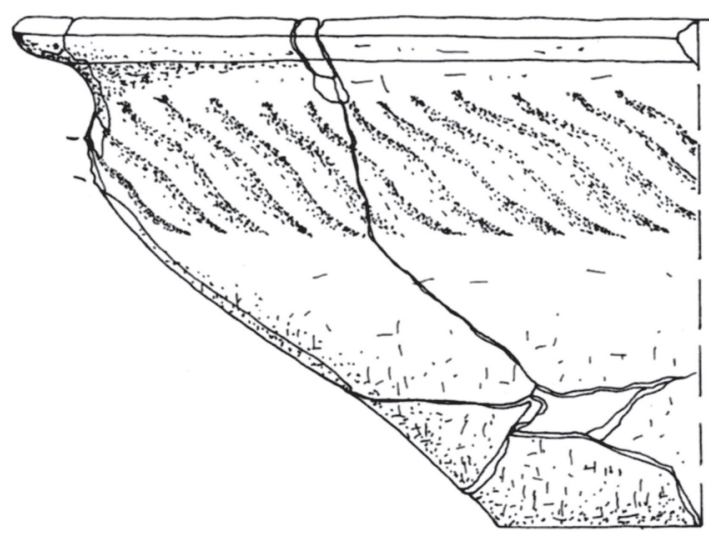

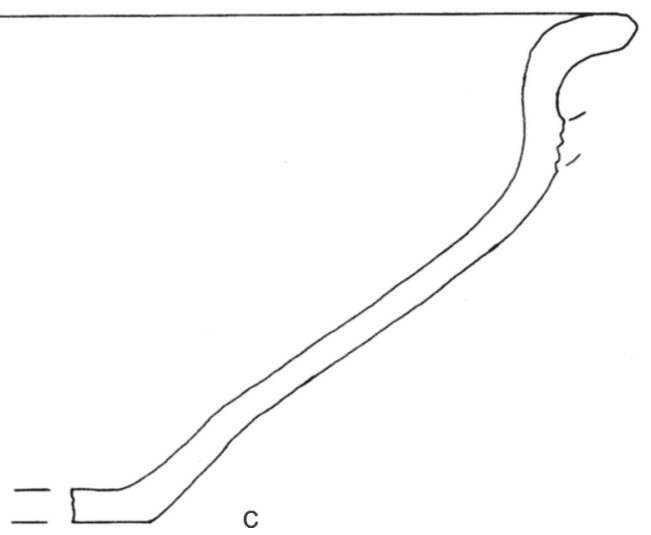

Abb. 8. Targowisko, Fst. 10. Inventar aus dem Grab 273 (nach Konieczny 2014). 
Die gleichen bzw. ähnlichen Funde mit transkarpatischen Analogien sind auch aus dem Bereich der Tarnobrzeg Lausitzer Kultur bekannt (Przybyła 2009a, 283-297). Das Auftauchen der besonderen Keramikart im sogenannten Stil Belegiš II auch auf den Gebieten westlichen Kleinpolens wurde neulich in der oben angeführten Veröffentlichung detailliert erörtert.

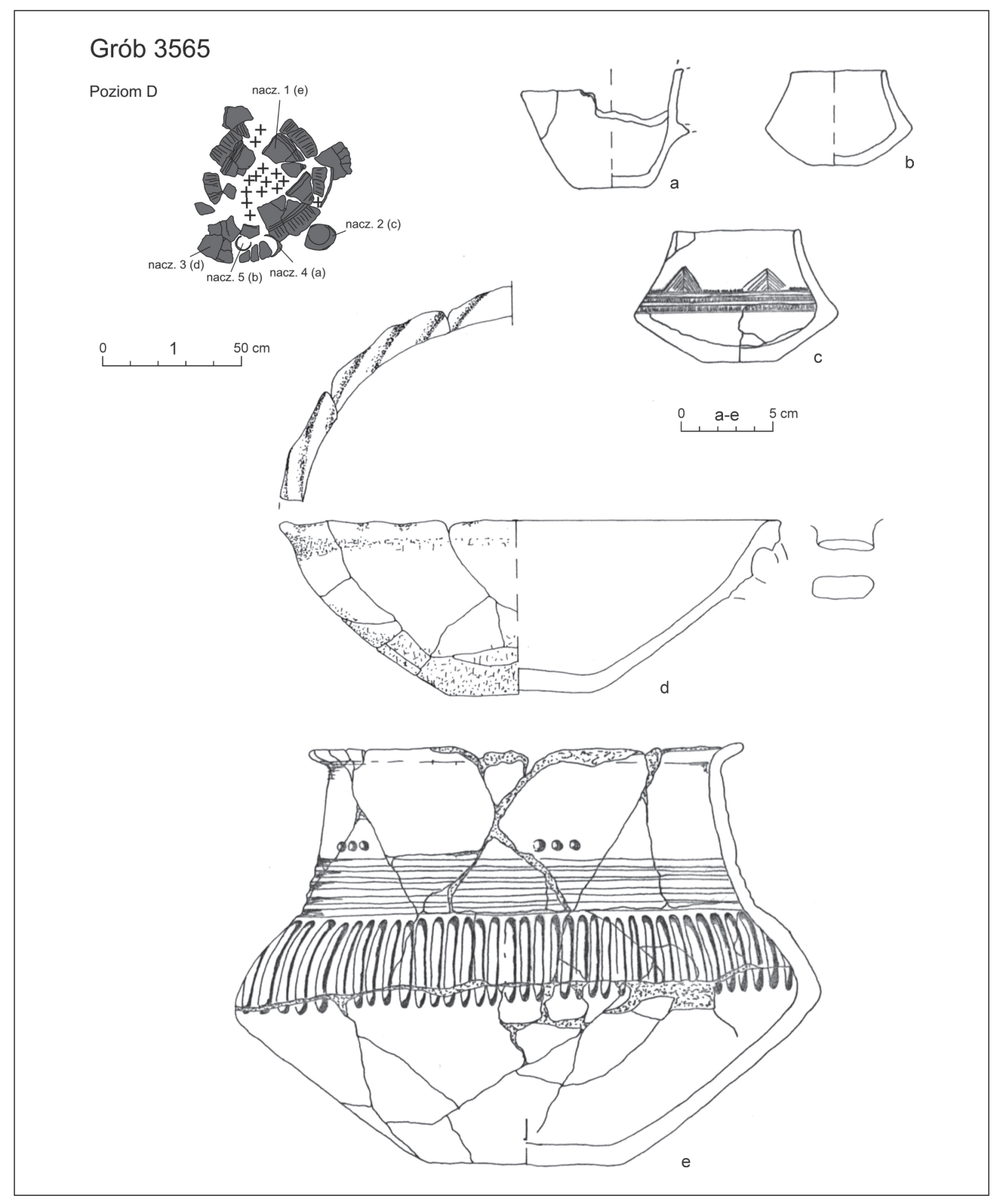

Abb. 9. Targowisko, Fst. 10. Inventar aus dem Grab 3565 (nach Konieczny 2014). 
Um die Zeitwende Ha A1 und Ha A2 kam es zu einer deutlicher Richtungsänderung beim Einfluss der Kulturmuster. Anstelle der Kontakte, die entlang der Ost-West-Achse verliefen, gewannen die Beziehungen zur Südzone an Bedeutung. Das besonders aussagekräftige Beispiel liefert ein Collier, das aus einem Halskettenschieber aus Bernstein, ca.380 Glasperlen und einem goldenen Drahtring bestand (Abb. 10; Purowski 2014).

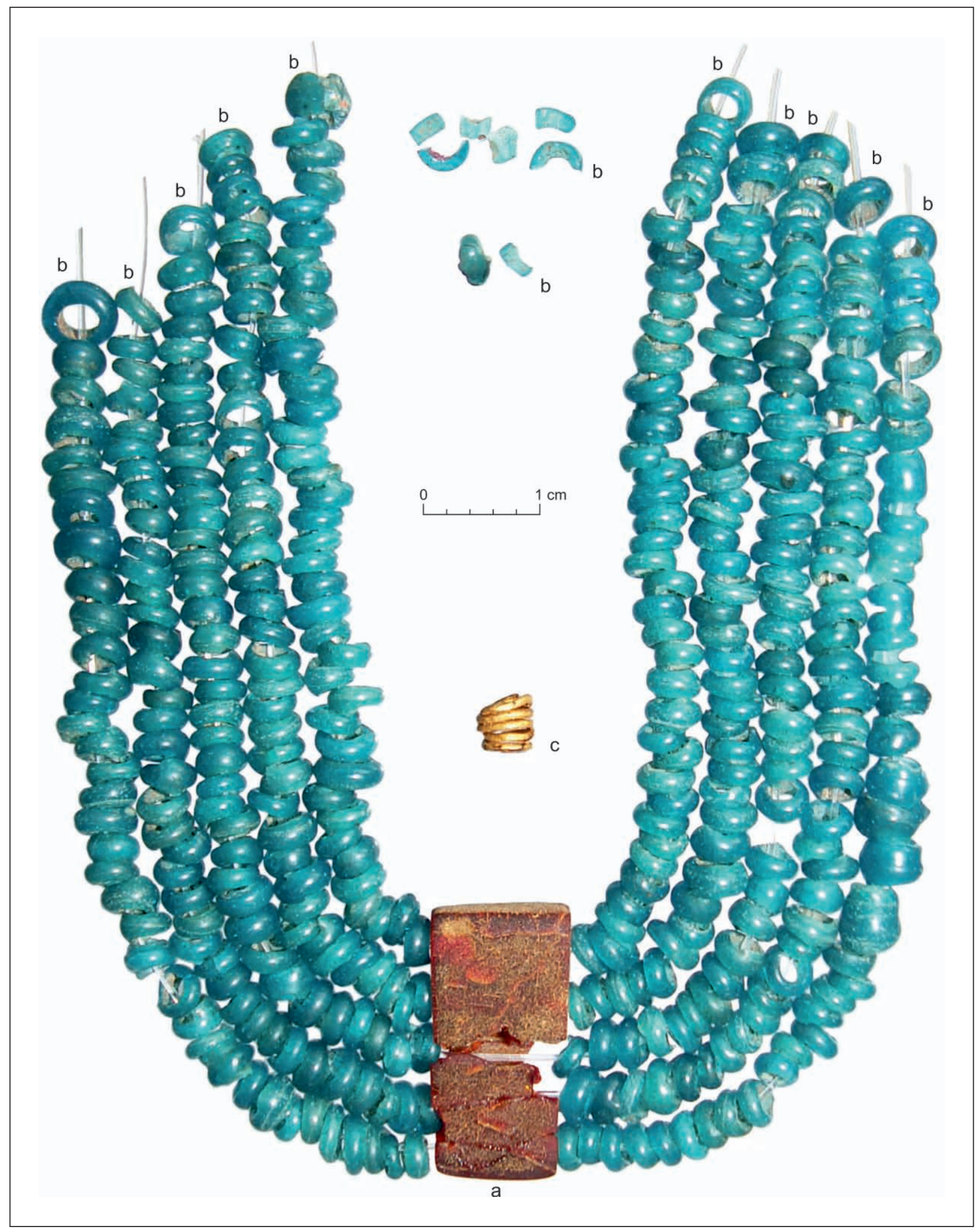

Abb. 10. Targowisko, Fst. 10. Kr. Wieliczka. Collier (nach Purowski 2014). 


\section{LITERATUR}

Bazielich 1982a

Bazielich $1982 b$

Bazielich 1984

Bazielich 1982

Blajer 1994

Blajer 1999

Essen 1985

Furmánek 1977

Gašaj 1985

Gawlik/Gryglewski 2010

Gedl 1967

Gedl 1975

Gedl 1982

Gedl 1998

Górski 2002

Górski 2003

Górski 2007

Górski 2010

Górski 2014

Górski 2012

Górski 2018

Górski/Makarowicz 2007

Górski/Schellner 2014

Konieczny 2014
M. Bazielich: Materiały kultury łużyckiej i kultury Gáva ze stanowiska $21 \mathrm{w}$ Zesławicach-Dłubni (Kraków-Nowa Huta). Wiadomości Archeologiczne 47, 1982, 91-106.

M. Bazielich: Materiały kultury łużyckiej i kultury Gáva odkryte na stanowisku 22 Zesławice-Dłubnia (Kraków-Nowa Huta). Wiadomości Archeologiczne 47, 1982, 71-90.

M. Bazielich: Elementy kultury Gáva w rejonie Krakowa-Nowej Huty. Archeologia Polski 29, 1984, 317-349.

M. Bazielich: Osada kultury łużyckiej w Nowej Hucie-Mogile na stan. 62. Część I - materiały. Materiały Archeologiczne Nowej Huty 15, 1992, 73-136.

W. Blajer: Przyczynek do zagadnienia powiązań Górnego Śląska i zachodniej Małopolski w III-IV okresie epoki brązu. Silesia Antiqua 36-37, 1994, $29-40$.

W. Blajer: Skarby ze starszej i środkowej epoki brazu na ziemiach polskich. Kraków 1999.

R. Essen: Die Nadeln in Polen II. Prähistorische Bronzefunde XIII/9. München 1985.

V. Furmánek: Pilinyer Kultur. Slovenská archeológia 25, 1977, 251-370.

D. Gašaj: Žiarové hroby pilinskej kultúry v Košiciach. Historica Carpathica 16, 1985, 309-317.

A. Gawlik/P. Godlewski: Elementy zakarpackie w materiałach wczesnołużyckich ze stan. $1 \mathrm{w}$ Witowie, gm. Koszyce. In: Transkarpackie kontakty kulturowe w epoce kamienia, brązu i wczesnej epoce żelaza. Krosno 2010, 331-352.

M. Gedl: Studia nad wczesną fazą kultury łużyckiej w środkowej i wschodniej Polsce. Archeologia Polski 12, 1967, 286-294.

M. Gedl: Kultura przedłużycka. Wrocław - Warszawa - Kraków - Gdańsk 1975.

M. Gedl: Periodyzacja i chronologia kultury łużyckiej w zachodniej Małopolsce, Południowa strefa kultury łużyckiej i powiazania tej kultury z Południe. Kraków Przemyśl 1982.

M. Gedl: Młodsza epoka brązu we wschodniej czéści polskich Karpat. Kraków 1998. J. Górski: Zmiana organizacji sieci osadniczej na obszarze Nowej Huty w środkowym okresie epoki brązu. Materiały Archeologiczne Nowej Huty 23, 2002, $17-$ 38.

J. Górski: Uwagi o datowaniu i kontekście znalezisk ceramiki o „cechach południowych" w strefie zasięgu kultury trzcinieckiej. In: Epoka brązu i wczesna epoka żelaza w Karpatach polskich. Krosno 2003, 89-137.

J. Górski: Chronologia kultury trzcinieckiej na lessach Niecki Nidziańskiej. Biblioteka Muzeum Archeologicznego w Krakowie 3. Kraków 2007.

J. Górski: Migration and Cultural Change. Western Lesser Poland in 1300-1200 BC. In: K. Dzięgielewski/M. S. Przybyła/A. Gawlik (Hrsg.): Migration in Bronze and Early Iron Age Europe. Prace Archeologiczne 63. Kraków 2010, 105-120.

J. Górski (Hrsg.): Kompleks osadniczy kultury tużyckiej w Targowisku, stan. 10-12, Kr. Wieliczka. Via Archaeologica. Źródła z badań wykopaliskowych na trasie autostrady A4 w Małopolsce. Kraków 2014.

J. Górski: Transkarpathian elements in the Trzciniec culture. Wanderings off people or ideas? In: R. Kujovský/V. Mitáš (Hrsg.): Václav Furmánek a doba bronzová. Zborník k sedemdesiatym narodeninám. Nitra 2012, 89-97.

J. Górski: Podkrakowska enklawa wczesnej kultury łużyckiej w świetle wyników najnowszych badań terenowych na trasie autostrady A4. Śląskie Sprawozdania Archeologiczne 60, 2018, 41-62.

J. Górski/P. Makarowicz: Reception of Transcarpathian influence in Trzciniec Cultural Circle as a Sign of Long-Distance Exchange Contacts. In: J. Baron/I. Lasak (Hrsg.): Long Distance Trade in the Bronze Age and Early Iron Age. Wrocław 2007, 101-116.

J. Górski/E. Schellner: Materiały osadowe kultury łużyckiej ze stanowiska $12 \mathrm{w}$ Targowisku, pow. wielicki. In: J. Górski (Hrsg.): Kompleks osadniczy kultury łużyckiej w Targowisku, stan. 10-12, pow. wielicki. Via Archaeologica. Źródła z badań wykopaliskowych na trasie autostrady A4 w Małopolsce. Kraków 2014, 81-102.

B. Konieczny: Cmentarzysko kultury łużyckiej z epoki brązu na stanowisku 1011 w Targowisku, Kr. Wieliczka. In: J. Górski (Hrsg.): Kompleks osadniczy kultury łużyckiej w Targowisku, stan. 10-12, Kr. Wieliczka. Via Archaeologica. Źródła z badań wykopaliskowych na trasie autostrady A4 w Małopolsce. Kraków 2014, 103-179. 
Kozłowski 1928

Kuśnierz 1989

Machnik 1993

Makarowicz 1999

Mrówka 2013

Przybyta 2007

Przybyła 2009a

Przybyła $2009 b$

Purowski 2014

Rachwaniec 1985

Rodak 2003

Rydzewski 1983

Szymaszkiewicz 1985
L. Kozłowski: Wczesna, starsza i środkowa epoka bronzu w Polsce w świetle subborealnego optimum klimatycznego i jego wpływ na ruchy etniczne $i$ zaludnienie Polski. Lwów 1928.

J. Kuśnierz: Dziobate siekierki z tulejką jako wyraz kontaktów ludności grupy tarnobrzeskiej kultury łużyckiej z obszarami wschodniej części Kotliny Karpackiej. In: Grupa tarnobrzeska kultury łużyckiej (Materiały z konferencji). Rzeszów 1989, 143-164.

J. Machnik: Główne etapy przemian kulturowych w początkach epoki brązu w Polsce południowo-wschodniej. In: Miscelanea archaeologica Thaddaeo Malinowski dedicata quae Franciscus Rożnowski redigendum curavit. Słupsk - Poznań 1993, 243 253.

P. Makarowicz: The Problem of Reception of Otomani Culture Patterns on the Polish Lowlands. In: Kultura Otomani-Füzesabony - rozwój, chronologia, gospodarka. Krosno 1999, 231-247.

Ł. Mrówka: Struktury osadnicze we wczesnych fazach kultury łużyckiej na Górnym Śląsku. Rzeszów 2013.

M. Przybyła: Początki późnej epoki brązu w dorzeczach Sanu i Cisy - chronologia, obraz kulturowy i transkarpackie powiązania. In: J. Chochorowski (Hrsg.): Studia nad epoka brazu i wczesna epoka żelaza w Europie. Księga poświęcona profesorowi Markowi Gedlowi na pięćdziesięciolecie pracy w Uniwersytecie Jagiellońskim. Kraków 2007, 571-640.

M. Przybyła: Intercultural contecst in the Western Carpathian area at the turn of the $2^{\text {nd }}$ and $1^{\text {st }}$ millennia BC. Warszawa 2009.

M. Przybyła: Uwagi o genezie grupy tarnobrzeskiej nad środkowym Sanem. In: Tarnobrzeska kultura łużycka - źródła i interpretacje. Rzeszów 2009, 53-86.

T. Purowski: Bursztynowy rozdzielacz i szklane paciorki odkryte w obiektach kultury łużyckiej w Targowisku, Kr. Wieliczka. In: J. Górski (Hrsg.): Kompleks osadniczy kultury tużyckiej w Targowisku, stan. 10-12, Kr. Wieliczka. Via Archaeologica. Źródła z badań wykopaliskowych na trasie autostrady A4 w Małopolsce. Kraków 2014, 289-305.

A. Rachwaniec: Materiały archeologiczne ze starszego okresu epoki brązu oraz kultury łużyckiej z rejonu Kopca Wandy w Nowej Hucie Mogile. Materiały Archeologiczne Nowej Huty 9, 1985, 89-191.

T. Rodak: Grób kultury pilińskiej ze stanowiska $1 \mathrm{w}$ Chełmie, powiat Bochnia. In: Epoka brazu i wczesna epoka żelaza w Karpatach polskich. Krosno 2003, 205-214. J. Rydzewski: Przemiany w zasiedleniu zachodniomałopolskich wyżyn lessowych w czasach od kultury łużyckiej do kultury przeworskiej. In: Przemiany ludnościowe i kulturowe I tysiaclecia p.n.e. na ziemiach między Odra a Dnieprem. Wrocław - Warszawa - Kraków - Gdańsk 1983, 213-240.

M. Szymaszkiewicz: Wstępne badania wykopaliskowe na cmentarzysku kultury pilińskiej w Chełmcu, gm. loco, woj. nowosądeckie. Acta Archaeologica Carpathica 24, 1982, 147-152.

\title{
Zo štúdia enkláv lužickej kultúry v oblasti Krakova Transkarpatské vplyvy
}

\author{
Jacek Górski
}

Súhrn

V severnej časti regiónu Malopol’ska bola v ranej fáze lužickej kultúry rozpoznaná krakovská podskupina sliezskej skupiny (Gedl 1975, 110). Predpokladá sa, že jej vývoj súvisí s obsadením oblasti Krakova obyvatel’stvom s črtami lužickej kultúry v dôsledku migrácie zo Sliezska a Moravy (obr. 1; nedávno Górski 2010). Silné vzt’ahy s územím Sliezska dokladajú aj predmety materiálnej kultúry. Súbor základných nádob má svoje ekvivalenty v západnej časti lužickej kultúry (obr. 2). To isté možno povedat’ aj o bronzových predmetoch (obr. 3). Tieto vzt̉ahy sú zrejmé najmä v prvých dvoch fázach - Iwanowice-Wysyłek a Zofipole-Raciborsko - datovaných do stupňov BD a HA1-HA2 (Gedl 1982, 21-24, 
obr. 13). Iná proveniencia bola zistená len v prípade sekier so symetrickými tulajkami (obr. 4). Datujú sa do stupňa HA (Kuśnierz 1986, 149). Početné paralely k týmto sekerám môžeme nájst’ najmä na Slovensku, v oblasti horného Považia a Popradu. Ich koncentrácia v tejto oblasti môže byt๋ dôsledkom miestnej výroby (Kuśnierz 1989, 144, 149, obr. 1). Počas nedávnych výskumov v Targowisku pred začatím stavby dial'nice A4 sa našlo niekol'ko krčahov s paralelami v pilinskej kultúre (obr. 5).

Na základe analýzy pohrebných súborov z tohto pohrebiska môžeme stanovit’ chronológiu prílevu keramiky s transkarpatskými znakmi (obr. 6; 7). Keramika z ranej fázy (Zofipole-Raciborsko) je vel’mi typická a reprezentujú ju dva jasne odlíšitel'né štýly (obr. 8; 9). Prvým je keramika s miestnymi prvkami. Sú to prevažne malé a tenkostenné zofipolské vázy zdobené vodorovnými rytými líniami a rôzne usporiadanými vpichmi. Pre druhý štýl nádob je charakteristická výzdoba širokými zvislými ryhami v spojení s ornamentálnymi motívmi.

Pre Malopol'sko platí, že, na prelome HA1 a HA2 došlo k reorientácii smerov, odkial' prúdili kultúrne vzorce. Namiesto kontaktov v smere východ - západ sa klúčovým stal príklon k južným oblastiam. Najpôsobivejším príkladom týchto väzieb je náhrdelník pozostávajúci z jantárového rozdelovača, asi z 380 sklenených korálikov a zo zvinutého zlatého drôtu (obr. 10).

Obr. 1. A - Expanzia lužickej kultúry do západného Malopol’ska. B - Sídlisková oblast’ včasnej fázy lužickej kultúry (šrafované) v susedstve uzavretej sídliskovej oblasti trzcinieckej kultúry v okolí Krakova (KT). Najstaršie lokality lužickej kultúry: 1 - Kraków-Nowa Huta; 2 - Książnice Wielkie; 3 - Witów; 4 - Iwanowice-Wysyłek; 5 - Zofipole a Igołomia; 6 - Kraków-Bieżanów; 7 - Zagórze; 8 - Brzezie; 9 - Targowisko.

Obr. 2. Porovnanie keramiky včasnej fázy lužickej kultúry z okolia Krakova (B) a z Kietrza, okr. Głubczyce (A; podla Gedl 1992; Górski 1994; 2014).

Obr. 3. Bronzové výrobky včasnej fázy lužickej kultúry z okolia Krakova (podla Górski 2007; Konieczny 2014).

Obr. 4. Sekery s tulajkami z okolia Krakova, výber. 1 - Chruszczyna Mała; 2 - Biskupice; 3 - Targowisko (podla Blajer 1999; Kuśnierz 1989).

Obr. 5. Džbány pilinskej kultúry z lokalít Targowisko (2-4) a Góra Chełm (1; podla Górski 2014; Rodak 2003).

Obr. 6. Korelačná tabela niektorých znakov na keramike z hrobových celkov na pohrebisku Targowisko (čierne štvoruholníky - výsledky pozitívnych vztahov); vysvetlivky pozri v texte k obr. 7 (podla Górski 2014, tab. 1).

Obr. 7. Targowisko, lokalita 10-12, okr. Wieliczka. Znaky na keramike pre obr. 6. A1 - bezuché amfory, kónické hrdlo, mierne stlačené vydutie; A2 - výzdoby vypnulinami charakteristiká pre „sliezsky štýl“; A3 - profilovaná misa s vpichmi na lome vydutia a/alebo s rytými líniami; A4 - váza s vpichmi na lome vydutia; A5 - hrniec s jemnou profiláciou alebo so zvýrazneným prechodom medzi vydutím a hrdlom; A6 - nezdobený pohár/džbán s ostrým lomom vydutia; B7 - zofipolská váza alebo jej fragment; B8 - dvojkónická váza s cylindrickým hrdlom; B9 - nádoba s vertikálnou žliabkovanou výzdobou; B10 - iné „južné” výzdobné motívy; B11 - nezdobená profilovaná misa s uchom alebo bez ucha; B12 - pohár; B13 - krokvicová výzdoba; B14 - kónická misa/šálka s uchom s cylindricky tvarovaným okrajom (podla Górski 2014, obr. 1).

Obr. 8. Targowisko, lokalita 10. Inventár z hrobu 273 (podla Konieczny 2014).

Obr. 9. Targowisko, lokalita 10. Inventár z hrobu 3565 (podla Konieczny 2014).

Obr. 10. Targowisko, lokalita 10, okr. Wieliczka. Náhrdelník (podla Purowski 2014).

Dr hab. Jacek Górski

Department of History and Cultural Heritage

University of Pope Jan Paweł II

ul. Kanonicza 9/202

PL - 31-002 Kraków

und

Archaeological Museum in Krakow

Senacka 3

PL - 31-002 Kraków

jacekgorski1500@gmail.com 
